\title{
2. Analysis of Normative Science
}

Normative SCIENCE is the study of what ought to be (1.281), that is, it sets up norms or rules which need not but ought to be followed (2.156). "Ought" then excludes compulsion, coercion, and determinism. It is always possible to act contrary to the "ought." The "ought" rather implies ideals, ends, purposes which attract and guide (1.575) deliberate conduct. Peirce sometimes refers to normative science as the science "which investigates the universal and necessary laws of the relation of phenomena to Ends ...” (5.121). Still, Peirce looks upon normative science as positive science, that is, as an inquiry which seeks for positive knowledge expressible in categorical propositions.

By a positive science I mean an inquiry which seeks for positive knowledge; that is, for such knowledge as may conveniently be expressed in a categorical proposition. Logic and the other normative sciences, although they ask, not what is but what ought to be, nevertheless are positive sciences since it is by asserting positive, categorical truth that they are able to show that what they call good really is so; and the right reason, right effort, and right being, of which they treat, derive that character from positive categorical fact. (5.39)

The statements of normative science, then, make a truth claim. They are founded in experience-that same experience upon which philosophy in general is founded, namely, "which presses in upon every one of us daily and hourly" (5.120). ${ }^{1}$

It is understandable, therefore, why Peirce sometimes describes normative science as that which treats of phenomena in their Secondness (cf. 5.123, 125, 110, 111). As a positive science, it deals with fact,

1 Yet in "Minute Logic" written shortly before the 1903 Harvard Lectures (that is, $c a .1902$ ), Peirce seems to have held a different, and perhaps incompatible view. See Appendix I for discussion of this passage. 
and fact is in the category of Secondness. Again, its proper and peculiar appreciations of the facts relate to the conformity of phenomena to ends (themselves not immanent in those phenomena) and this is another dyadic relation or Secondness (5.126). In terms of the relation of phenomena to ends, normative science enables one deliberately to approve or disapprove certain lines of conduct. Thus it is the science which separates the sheep from the goats, makes the dichotomy of good and bad (cf. 5.37, 110, 111). From every viewpoint normative science involves an "emphatic dualism" (cf. 5.551).

Since normative science deals with "ought," that is, with deliberate conduct, and since it allows one to make value judgments concerning such conduct, one might be tempted to look upon it as an art or a practical science. We have seen that for many years Peirce himself so considered ethics (cf. 5.111). Yet Peirce insists again and again that normative science is purely theoretical, indeed, "the very most purely theoretical of purely theoretical sciences" (1.282; cf. 1.575, $5.125)$. To say that knowledge of normative science would directly and in itself either help one to think more correctly or to live more decently or to create more artistically, would be like saying that a knowledge of the mechanics involved in a game of billiards would allow us to become a master player (cf. e.g. 2.3). A vast knowledge of physics does not make a good mechanic, nor is it so intended. Normative science looks primarily to an understanding of certain sets of conditions. Of course Peirce sees and explicitly says that normative science is closely related to art (1.575) and that there are "practical sciences of reasoning and investigation, of the conduct of life, and of the production of works of art" (5.125) which correspond to the normative sciences, "and may be probably expected to receive aid from them" (5.125).

But they are not integrant parts of these sciences; and the reason that they are not so, thank you, is no mere formalism, but is this, that it will be in general quite different mentwo knots of men not apt to consort the one with the other -who will conduct the two kinds of inquiry. (5.125)

Normative science, then, is theoretical, and according to Peirce that is precisely why it is called and must be called "normative" (1.281). Its business is analysis or definition (1.575). 
Peirce feels obliged to emphasize that normative science is not a special science. It is a subdivision of philosophy and as such relies on data available to anyone at any time by reflection upon experience. It does not require specialized techniques or apparatus for its observations as do physics or chemistry or psychology. Furthermore, he insists that while now and then philosophy may make use of such special data it is not significantly aided thereby-not even by the results of psychology $(5.125,3.428)$. Thus, Peirce frequently argues, the science of logic, contrary to the opinion of the German school, ${ }^{2}$ cannot be reduced to a matter of feeling. Ultimately, an argument cannot be judged valid because of some instinctive feeling that it is so, nor by any compulsion so to judge, nor by appeal to an intuition (cf. $2.155 \mathrm{ff}$., $2.19,2.39-51,3.432$ ). In general, the psychological fact that men for the most part show a natural tendency to approve the same arguments which logic approves, the same acts which ethics approves, and the same works of art which esthetics approves is insufficient support for the conclusions of those sciences. And if one were to urge in a particular case, let us say, that something is logically sound, simply because men have a strong and imperious tendency to think so, one would be arguing fallaciously (5.125). It would be much like arguing for the truth of a proposition from the certitude which one has about it, instead of justifying one's certitude by establishing the truth of the proposition. Or to put the difficulty (and its solution) quite clearly in Peirce's own terms:

By the theory of cognition is usually meant an explanation of the possibility of knowledge drawn from principles of psychology. Now, the only sound psychology being a special science, which ought itself to be based upon a well-grounded logic, it is indeed a vicious circle to make logic rest upon a theory of cognition so understood. But there is a much more general doctrine to which the name theory of cognition might be applied. Namely, it is that speculative grammar, or analysis of the nature of assertion, which rests upon

2 E.g. Schröder, Sigwart, Wundt, Schuppe, Erdmann, Bergmann, Glogau, Husserl. Peirce opposes to this group the "English logicians," Boole, De Morgan, J. S. Mill, Venn (cf. "Why Study Logic"). And yet Peirce is very critical of J. S. Mill for "psychologizing" (cf. 2.39-51). 
observations, indeed, but upon observations of the rudest kind, open to the eye of every attentive person who is familiar with the use of language, and which, we may be sure, no rational being, able to converse at all with his fellows, and so to express a doubt of anything, will ever have any doubt. (3.432)

In a later paper (written $c a$. 1906) Peirce makes exactly the same observations and adds a distinction which is quite to the purpose. He says that those logicians who make logic rest on psychology confound psychical truths with psychological truths (5.485). Of course, logic rests upon the former since they are observational data ("of the rudest kind") with which speculative grammar deals. It is such psychical truths which Peirce has in mind when he explicitly admits that there is in a sense a compulsion at the base of logic, a compulsion arising from positive observation of a factual situation, not a compulsion of mere feeling, nor a compulsion based on the principles of another theoretical science.

But logic begins to be a positive science; since there are some things in regard to which the logician is not free to suppose that they are or are not; but acknowledges a compulsion upon him to assert the one and deny the other. Thus, the logician is forced by positive observation to admit that there is such a thing as doubt, that some propositions are false, etc. But with this compulsion comes a corresponding responsibility upon him not to admit anything which he is not forced to admit. (3.428)

The mistake of the psychologizing logicians is not so much to recognize the presence of compulsion of some sort, but to make logical consequentiality consist in "compulsion of thought" (3.432). ${ }^{3}$

Peirce warned his reader that if he did not see that normative science deals with phenomena in their Secondness, the reason lay in a too narrow conception of that branch of philosophy (5.123). He

3 See also 2.47-48 and cf. Richard J. Bernstein, "Peirce's Theory of Perception" in Studies, Moore and Robin, pp. 165-189, for a thorough analysis of role of "compulsion" in authenticating perceptual judgments. Certitude is not a sign of nor a guarantee of truth. 
takes care to point out two ways in which modern philosophy generally misconstrues the nature of normative science. In the passages we are about to consider his references to these errors are exceedingly brief and so are enigmatic. A certain amount of explanation is necessary to understand why Peirce considers them so important and to realize in what ways they differ radically from his own views. The first mistake, according to Peirce, is to think that normative science's chief and only concern is to differentiate goodness and badness and to say to what degree a given phenomenon is good or bad. The error here is to think of normative science mathematically or quantitatively, instead of qualitatively. The distinctions which are of interest in normative science are those of kind, not of degree. Thus Peirce says that logic, in classifying arguments, recognizes different kinds of truth; ethics admits of qualities of good; and esthetics is so concerned with qualitative differences "that, [when they are] abstracted from, it is impossible to say that there is any appearance which is not esthetically good" (5.127). Briefly, the important question for normative science is not how good something is, but whether it is good at all. Peirce calls this "negative goodness" or "freedom from fault."

I hardly need remind you that goodness, whether esthetic, moral, or logical, may either be negative-consisting in freedom from fault-or quantitative-consisting in the degree to which it attains. But in an inquiry, such as we are now engaged upon, the negative goodness is the important thing. (5.127).

Perhaps the reader is asking this question: why does Peirce consider it so important to mention a point which seems almost obvious? What is back of it? A tentative suggestion comes to mind: the doctrine of continuity. A quantitative treatment of goodness (or badness) would suppose that it comes in discrete packages, whereas in reality goodness is a continuum. In a certain sense goodness (or badness) does not admit of degrees. It is of the nature of a quality-of a Firstness-and is what it is without reference to anything else. To be sure, goodness involves a complex relation (e.g. between ends, means, intention, and circumstances), but the goodness qua goodness is an undifferentiated quality. Thus the old scholastic maxim: bonum ex integra causa; malum ex quocumque defectu. Nor does this insight 
into the continuity of goodness conflict with our use of comparative and the superlative degrees of the adjective "good," because they refer to a concrete subject participating or sharing in goodness and not to the quality itself. Again, Peirce would not deny that one might be able to set up a quantitative scale of measurement to indicate the degree in which a certain set of concrete subjects share in goodness, but he would insist that such a scale is always somewhat arbitrary and can never claim exactitude.

The second mistake of modern philosophy in this matter is to think that normative science relates exclusively to the human mind.

The beautiful is conceived to be relative to human taste, right and wrong concern human conduct alone, logic deals with human reasoning. (5.128)

Peirce tells us that in the truest sense these sciences are sciences of mind, but that the mistake is to think of mind in the narrow Cartesian way as something which "resides" in the pineal gland.

Everybody laughs at this nowadays, and yet everybody continues to think of mind in this same general way, as something within this person or that, belonging to him and correlative to the real world. A whole course of lectures would be required to expose this error. I can only hint that if you reflect upon it, without being dominated by preconceived ideas, you will soon begin to perceive that it is a very narrow view of mind. I should think it must appear so to anybody who was sufficiently soaked in the Critic of the Pure Reason. (5.128)

Indeed it would take "a whole course of lectures" to present Peirce's theory of mind. Clearly, however, Peirce is here making the same point he made in his letter to James (8.256) where he labeled as nominalistic (and hence erroneous) the notion that thought is in consciousness rather than consciousness in thought. Mind is thought, and thought is Thirdness, and Thirdness is ubiquitous. The human mind is only one manifestation of Mind, perhaps the highest because it has the greatest capacity for self-control, but not unique. Here again Peirce is insisting upon the continuity of reality. If mind is anywhere, 
it is everywhere in one form or another. It is true, however, that in his own usage of the term he is not always so careful as not to fall into the Cartesian usage.

Peirce accepted the traditional division of normative science into three disciplines: esthetics, ethics, and logic, but added his own meanings to them. This division was in his eyes by no means arbitrary. It had an inner logic dictated by the very process of reasoning itself. To appreciate fully the great importance Peirce attached to these three disciplines it is necessary to examine their close interrelation. It will become evident, too, that what Peirce means by esthetics, ethics, and logic is not exactly what had been traditionally meant. He tended to keep the terminology because it was close enough to his own conception to introduce the reader and direct his attention toward the general area he was to discuss. ${ }^{4}$ It should become clear as we proceed that Peirce's early hesitation to call ethics a theoretical science and his persistent doubts about the nature of esthetics can be traced to a confusion in his own mind and in the literature he read as to what these subjects treat.

Let us begin, then, by examining at length one of Peirce's earliest presentations of the divisions of normative science and their interrelation. In his manuscript, "Minute Logic" (ca. 1902), he explains that after a study of phenomenology one must undertake "the logic of the normative sciences, of which logic itself is only the third, being preceded by Esthetics and Ethics" (2.197). He tells us that he had only recently come to realize the importance of esthetics in logical theory and that he is not completely clear about the matter yet himself (see above). He goes on to say, as we have seen, that for a long time he had looked upon ethics as an art and again that only recently had he come to appreciate its role as a theoretical science and its connection with logic (2.198). He had up till then not clearly distinguished ethics from morality. His mistake was to think ethics was correctly defined as the science of right and wrong. Only when he realized that these are themselves ethical conceptions did he see that they could not be used to define ethics.

4 We have already remarked that Peirce did ultimately substitute the term "practics" for "ethics" and warned the reader repeatedly that his use of the terms "logic" and "esthetics" was peculiar. Evidently, he just could not think of better designations. 
We are too apt to define ethics to ourselves as the science of right and wrong. That cannot be correct, for the reason that right and wrong are ethical conceptions which it is the business of that science to develope and to justify. A science cannot have for its fundamental problem to distribute objects among categories of its own creation; for underlying that problem must be the task of establishing those categories. (2.198)

Ethics, then, is not concerned directly with pronouncing this course of action right and that wrong, but with determining what makes right right and wrong wrong. It has to do with norms or ideals in terms of which those categories have meaning. Peirce therefore came to see ethics as the science of ends.

The fundamental problem of ethics is not, therefore, What is right, but, What am I prepared deliberately to accept as the statement of what I want to do, what am I to aim at, what am I after? . . . It is Ethics which defines that end. (2.198)

Now it becomes clear just what is the relation of ethics to logic. Logic deals with thinking and thinking is a kind of deliberate activity. It, therefore, has an end. But if ethics is the science which defines the end of any deliberate activity, it also defines the end of thinking. Logic is a study of the means of attaining that end, that is, the study of sound and valid reasoning. ${ }^{5}$ The dependence of logic on ethics, therefore, is apparent. Thus Peirce concludes, "It is, therefore, impossible to be thoroughly and rationally logical except upon an ethical basis" (2.198).

A similar line of reasoning holds good for esthetics. Peirce began to appreciate its importance as a theoretical science and the foundation of ethics only when he began to realize that it should no more be defined in terms of beauty than ethics in terms of right. The reason is the same: the beautiful and the ugly are categories within esthetics. It is precisely these categories which esthetics must establish and

5 Peirce later defines normative science as science of ends. Here he says logic is a science of means. Means, however, are themselves subordinate or partial ends. Thus reasoning has its own end, attaining truth, yet relative to action it is a means. 
justify. Again esthetics, as a theoretical discipline, does not judge this or that to be beautiful or ugly, but tries to decide what makes the beautiful beautiful, and the ugly ugly. It has to do with norms and ideals in terms of which we can define and ultimately apply those categories. And so it is closely allied with ethics. Peirce reasons this way:

Ethics asks to what end all effort shall be directed. That question obviously depends upon the question what it would be that, independently of the effort, we should like to experience. But in order to state the question of esthetics in its purity, we should eliminate from it, not merely all consideration of effort, but all consideration of action and reaction, including all consideration of our receiving pleasure, everything in short, belonging to the opposition of the ego and the non-ego. (2.199)

Esthetics, then, deals with ends (or more properly the end) in themselves. It studies the admirable per se, regardless of any other consideration. This is the ideal of ideals, the summum bonum. ${ }^{6}$ As such it needs no justification, it is what it is and gives meaning to the rest. As such it belongs to the category of Firstness. English has no suitable word for it, Peirce observes, but the Greek kalos comes close. "Beautiful" will not do because kalos must include the unbeautiful as well. Whatever term may be chosen to express it, the question of esthetics is to determine what is admirable, and so desirable, in and for itself (2.199).

Upon this question ethics must depend, just as logic must depend upon ethics. Esthetics, therefore, although I have terribly neglected it, appears to be possibly the first indispensable propedeutic to logic .... (2.199)

Peirce's position in this section of the "Minute Logic" is clear enough and makes good sense in terms of his revised notions of ethics

6 The summum bonum ought not to be thought of as simply another member in a series of goods, not even the last member. Peirce is not always as clear as might be desired in the way he uses the term, but as we shall see as we continue our analysis he did not fall into that mistake. Cf. H. W. Schneider, "Fourthness," Studies, Wiener and Young, p. 211. 
and esthetics. Human action is reasoned action; but reasoned action is deliberate and controlled. Deliberate and controlled action is action governed by ends; but ends themselves may be chosen and that choice, in order to be rational, must be deliberate and controlled. This ultimately requires the recognition of something admirable in itself. Logic, as the study of correct reasoning, is the science of the means of acting reasonably. Ethics aids and guides logic by analyzing the ends to which those means should be directed. Finally, esthetics guides ethics by defining what is an end in itself, and so admirable and desirable in any and all circumstances regardless of any other consideration whatsoever. As we shall see, Peirce concludes that this summum bonum is nothing else than reasoned and reasonable conduct. Ethics and logic are specifications of esthetics. Ethics proposes what goals man may reasonably choose in various circumstances, while logic proposes what means are available to pursue those ends.

A problem arises, however, as we read on in the "Minute Logic." Chapter 4 deals specifically with normative science and in it Peirce seems to contradict what he had said previously. There he seems to deny that pure ethics or esthetics are normative sciences at all. $\mathrm{He}$ seems to say that only logic is truly normative. Is there any way around the apparent inconsistency?

Peirce begins this chapter by enumerating various general positions concerning the number and nature of divisions of normative science. Everyone is agreed that logic is normative. The majority of writers also include esthetics and ethics, so that the division corresponds to the ancient triad of ideals: the true, the beautiful, and the good. Others, however, admit only two normative sciences, namely, logic and ethics. The former would consider the conformity of thought to being; the latter the conformity of being to thought. According to this position logic and ethics are normative precisely because nothing can be logically true or morally good without a purpose to be so. Thus the conformity therein involved is controlled and deliberate. But such control seems to be conspicuously lacking when it is a question of something being beautiful or ugly. It simply is beautiful or is ugly without any purpose so to be. Consequently, on this sort of analysis esthetics is excluded from the trio (1.575).

Finally, there seems to be some doubt as to whether ethics is truly normative. The subject matter of pure ethics is not "right and 
wrong" nor "duties and rights." These are practical matters which make "heavy drafts upon wisdom" (1.577). No, these questions are a superstructure raised upon the foundations of pure ethics. The question at the center of pure ethics is, "What is good?" and this is not normative, but pre-normative. The reason is, Peirce explains, that

It does not ask for the conditions of fulfillment of a definitely accepted purpose, but asks what is to be sought, not for a reason, but back of every reason. Logic, as a true normative science, supposes the question of what is to be aimed at to be already answered before it could itself have been called into being. Pure ethics, philosophical ethics, is not normative, but pre-normative. (1.577)

It certainly seems that here Peirce makes logic the only true normative science. This is not to deny, however, that it depends on the answer which ethics gives to the pre-normative question, "What is good?" And there is no use objecting that logic already has its own object, truth, because in the final analysis logic must face the question "What is truth?" In other words, just what is it that logic seeks? And, of course, this involves the question of ethics in a particular context: truth is a good (1.578-579). Truth is nothing but a phase of the summum bonum, the subject of pure ethics (1.575).

There is a real difficulty in reconciling this chapter with the earlier one. The problem stems from Peirce's inability to decide clearly, once and for all, just what is to be included in the discipline called "ethics." $\mathrm{He}$ is searching in this work and will continue to search until near the very end of his career when he will discard that terminology altogether. The same is true of his presentation of esthetics, but his difficulty is more acute. The reader will have perhaps already remarked that in the passages just discussed what Peirce deems pure, pre-normative, ethics in Chapter 4 sounds very much like the esthetics he discussed in an earlier chapter. Nevertheless, the inconsistencies which one would expect to find in an original theory (at least in the first stages of articulation) are not destructive of the essential insight which Peirce is trying to express. Certain clear gains have been made and the line of thought is beginning to emerge. Furthermore, some remarks can be made which diminish somewhat the confusion these inconsistencies may cause. 
In the first place, in reading the "Minute Logic," one must remember that it is a book on logic. Consequently, logic will be the center of attention and the main perspective from which the entire work will be developed. Thus, for example, in the section entitled "Why Study Logic?" Peirce says that he is to treat, not precisely the normative sciences, but "the logic of the normative sciences" (2.198, emphasis added). So too, when he points out the importance of esthetics as "propedeutic to logic" he concludes that "the logic of esthetics" ought not be omitted from the science of logic (2.199, emphasis added). This fact might help us to understand in part why Peirce, in Chapter 4, makes esthetics and ethics pre-normative. His main interest is logical; logic for certain is a "true normative science;" esthetics and ethics are necessary "propedeutics;" hence from that point of view one could think of them as in a sense pre-normativethat is, pre-logical. There is some textual evidence that Peirce was thinking of the topic in this way. Thus, after he reviewed the current opinions as to the number of normative sciences, he remarks:

Those writers, however, who stand out for the trinity of normative sciences do so upon the ground that they correspond to three fundamental categories of objects of desire. As to that, the logician may be exempted from inquiring whether the beautiful is a distinct ideal or not; but he is bound to say how it may be with the true . . . . (1.575)

Peirce, then, writing as a logician, explicitly disclaims any responsibility for settling the question of the number of normative sciences. The only point he feels obliged to make is that the true is an aspect of the good and that therefore logic can be studied satisfactorily only once it has taken into consideration its purpose and end.

In the second place, Peirce identifies the usual tripartite division of normative science in his chapter on ethics with positions he had criticized earlier. This is clearly the case in his discussion of esthetics, and a case, less strong perhaps, might also be made for what he says about ethics. Remember that he said that the usual division of the normative sciences into logic, ethics, and esthetics makes their objects the true, the good, and the beautiful. Yet earlier he had said that esthetics had been seriously handicapped by its definition as the science of the beautiful. Now the apparent inconsistency with respect 
to what Peirce says about esthetics might be diminished if we look at it this way: those who (like Schleiermacher) would exclude esthetics from the normative sciences are correct if esthetics is taken to be concerned with the doctrine of the beautiful. The reason would be simply this: if the beautiful is the subject about which esthetics concerns itself and not merely a category within that science, it must be an ultimate, self-justifying category, and as such could be known only through intuition. There could be no argument about it; it could not be subjected to any criticism; there could be no legitimate and resolvable difference of opinion. One would see that $\mathrm{X}$ is beautiful or he would not. In other words, esthetics could not be a science which would allow one to decide and to judge that something is beautiful or not. It would not be normative at all; it would be only phenomenological. The beautiful would be a "non-natural quality" and any attempt to analyze it would be to fall into the "naturalistic fallacy." On this view, then, it would be correct to say that esthetics is not normative, but perhaps pre-normative. On the other hand, if, as Peirce did in the earlier section of the "Minute Logic," one defined esthetics as the science of the admirable per se, it could be considered normative precisely because it investigates the ideal, in terms of which one could separate the sheep from the goats, the beautiful from the ugly, and defend and justify that discriminatory judgment in terms of a norm. It is doubtful whether Peirce saw this distinction clearly here because in a later discussion he will still be struggling with the question of whether there can be such a thing as esthetic goodness and badness. Yet if it is admitted that this analysis could have been lurking just behind the clarity of consciousness, then all that would have been necessary for Peirce to avoid his apparent inconsistency would have been to state that he was discussing two different conceptions of esthetics.

A similar, although perhaps a less convincing, case might be made out for what he says about ethics. The difficulty here, however, is that the former mistake to which he objected was not in defining ethics as concerned with the good, but as concerned with right and wrong, duties and rights. Still, although he is not as explicit about it as in the case of esthetics, we think that his thinking is the same. For if one takes the good as the object of ethical study and not as a category within the science, again it becomes an ultimate, which cannot 


\section{PEIRCE ON NORMS AND IDEALS}

be judged but merely recognized. Such a study cannot be normative, but only pre-normative. It cannot justify the distinction of good and bad, it can only intuit it as a primitive given. Again we have the familiar notion of G. E. Moore. If Peirce had this in mind as the paradigm of theoretical ethics when he wrote the fourth chapter of the "Minute Logic," it is understandable why he looked upon ethics as pre-normative. On the other hand, if in the earlier section he was objecting to the indescribability of goodness, and rejecting at least implicitly the "naturalistic fallacy" as no fallacy at all, then he would be justified in making ethics a theoretical, normative science, a science of ends, in terms of which one might judge goodness and badness, in so far as goodness and badness were not "non-natural" properties but relations of conformity and disconformity to ends. ${ }^{7}$

In any case Peirce has made this significant gain: he has seen that truth and goodness are intimately connected. He will exploit this insight in his Pragmatism Lectures of 1903. There he will strive to show that logic, ethics, and esthetics deal with three kinds of goodness, and that this goodness is ultimately reasonableness manifesting

7 We suspect that what Peirce is trying to express is something akin to the scholastic distinction between transcendental and predicamental categories. Traditionally the scholastics looked upon Oneness, Truth, and Goodness (some included Beauty) as the absolutely universal categories which attached to being as being independently of and thus cutting across all genera and species. These transcendental categories are not really distinct from being itself, but are merely three aspects of it, three ways in which man can consider it. When these transcendentals are predicated of this or that being they are so by analogy. Because these categories are transcendental, they can only be discovered by phenomenological analysis. The scholastics distinguished between these ultimate, absolutely universal categories and particular categories affine to the former. Thus, for example, they distinguished logical and moral truth from one another and from the universal category, ontological truth. Again they distinguished moral or ethical goodness from ontological goodness. The normative sciences of logic and ethics, in terms of the transcendental categories of truth and goodness, set up norms for deciding the logical truth or falsity of propositions and arguments, and for deciding the moral goodness or badness of such and such deliberate conduct. Perhaps Peirce was unconsciously sliding from one type of category to the other, and thus at one time saw ethics as prenormative and at another as normative. 
itself in three different ways. Let us consider in some detail what he had to say in those famous lectures.

In the first lecture, "Pragmatism: The Normative Sciences," Peirce again tells us that traditionally the normative sciences have been numbered as three, logic, ethics, and esthetics, and that he will continue to employ those terms. He characterizes these sciences as those which distinguish good and bad in the representations of truth, in the efforts of the will, and in objects regarded simply in their presentation, respectively (5.36). Thus he begins to develop explicitly the notion that the sciences in question all deal with kinds of goodness.

The purpose of this first lecture was to sketch the connection between his form of pragmatism and the normative sciences. Although we will examine this essential point in detail later in this chapter, it is necessary for our understanding of the doctrine of normative science to consider how Peirce laid out his thought in this matter. After having expounded his maxim, he makes this important inference:

For if, as pragmatism teaches us, what we think is to be interpreted in terms of what we are prepared to do, then surely logic, or the doctrine of what we ought to think, must be an application of the doctrine of what we deliberately choose to do, which is Ethics. (5.35)

Pragmatism is a doctrine of logic. It is a logical method helping us to know just what we think, just what we believe. Our thought's meaning is to be interpreted in terms of our willingness to act upon that thought-it is to be interpreted in terms of its conceived consequences. Peirce, then, sees a connection between thinking and doing, and so a connection between good thinking and good doing. What we are prepared to accept as proper conduct, good conduct, approvable conduct, as the interpretant of our thinking, must be the measure of proper, good, acceptable, logical thinking. Thus logic depends upon ethics. But in its turn ethics must depend upon something else. Conduct is approved or disapproved to the degree that it conforms or fails to conform to some purpose, but the question remains as to what purposes are to be adopted in the first place. 
But we cannot get any clue to the secret of Ethics ... until we have first made up our formula for what it is that we are prepared to admire. I do not care what doctrine of ethics be embraced, it will always be so. (5.36)

To determine what we are prepared to admire, what is admirable per se, is the task of esthetics.

It [Ethics] supposes that there is some ideal state of things which, regardless of how it should be brought about and independently of any ulterior reason whatsoever, is held to be good or fine. In short, ethics must rest upon a doctrine which, without at all considering what our conduct is to be, divides ideally possible states of things into two classes, those that would be admirable and those that would be unadmirable, and undertakes to define what it is that constitutes the admirableness of an ideal. (5.36)

Esthetics, then, attempts to analyze the summum bonum, the absolutely ideal state of things which is desirable in and for itself regardless of any other consideration whatsoever. Esthetics studies the ideal in itself, ethics the relation of conduct to the ideal, and logic the relation of thinking to approved conduct. ${ }^{8}$

In the following lectures in the series Peirce continues to hammer home the key insight into the normative sciences: they all have to do with goodness and badness, with approval and disapproval. Thus the essence of logic is to criticize arguments, that is, to pronounce them acceptable or not, good or bad (5.108). But to say that certain arguments are good or bad implies that they are subject to control. It

8 It must not be imagined that esthetics and ethics do not involve logic. They do because they are theoretical sciences. Therefore, it would be incorrect to think that Peirce held for a purely emotive conception of ethics, or a purely subjective conception of esthetics (not to be confused with mere taste). All three normative sciences involve deliberate approval, and hence are based on reasoning. The distinction to be kept in mind is that between logica utens and logica docens which Peirce himself never tires of making. Logic as a normative science is docens-a thinking about thinking wherever it may occur. That Peirce was aware of the possibility of confusion on this point is evidenced by his constant rebuttal of any type of hedonism as illogical and hence unreasonable. 
supposes that in the future we can avoid using bad arguments and strive to use good ones. Indeed, the very notion of criticism implies the ability to control and to correct.

Any operation which cannot be controlled, any conclusion which is not abandoned, not merely as soon as criticism has pronounced against it, but in the very act of pronouncing that decree, is not the nature of rational inference-is not reasoning. Reasoning as deliberate is essentially critical, and it is idle to criticize as good or bad that which cannot be controlled. Reasoning essentially involves self-control; so that the logica utens is a particular species of morality. (5.108)

The distinction between logical truth and falsity, then, is nothing but the distinction between logical goodness and badness, which in turn is only a special case of moral goodness and badness.

This is the very heart of the matter. It is the very heart of Peirce's logic and of his entire philosophical outlook. To make a normative judgment is to criticize; to criticize is to attempt to correct; to attempt to correct supposes a measure of control over what is criticized in the first place. Any other kind of criticism, any other conception of goodness and badness is idle (cf. 2.26). In this Peirce was directly opposed to almost all other schools of thought of his day. ${ }^{9}$ Two of these positions Peirce considered to be of particular importance because their objections to his own position are serious and not easily answered. The first objection says that Peirce's position makes logic a question of psychology (5.110). This is J. S. Mill's view and one which Peirce criticized at length again and again (see e.g. 2.47-51). The principle on which Mill based his opinion is that to say how a man ought to think has to be based ultimately on how he must think. In the passage we are now examining Peirce does not take up a detailed reply. In like manner, we will content ourselves with Peirce's simple denial of the allegation.

The first [objection] is that this [Peirce's position] is making logic a question of psychology. But this I deny. Logic does

${ }^{9}$ For Peirce's survey of opinions, 13 in all, see 2.19-78. 
rest on certain facts of experience among which are facts about men, but not upon any theory about the human mind or any theory to explain facts. (5.110)

Psychology, like any science, theorizes about facts. In Peirce's view, logic itself theorizes about facts and not about another theory. The second objection is more serious and on Peirce's own admission deceived him for many years (5.111). It argues that by making logic dependent upon ethics, and ethics dependent upon esthetics, Peirce in effect has fallen into the error of hedonism. What is more, such an hierarchical arrangement of the normative sciences involves a basic confusion of the categories of Firstness and Secondness (5.110). Clearly this objection is a difficulty which Peirce proposed to himself and which prevented him for a long time from seeing the importance of normative science for his own thought. On the one hand, he had been convinced from early in his career of the error of hedonism, and on the other hand, he did not clearly see how to avoid an inconsistency in his doctrine of the categories if he accepted the traditional triple division of normative science. ${ }^{10}$ Let us consider in some detail, then, how Peirce resolved this problem.

The answer came to him through a more penetrating analysis of his categories. He began to realize that one can and does have a representation of a Second or a First as well as of a Third. With this new light it was clear to him that

To say that morality, in the last resort, comes to an esthetic judgment is not hedonism-but is directly opposed to hedonism. (5.111)

How is this so? Consider the phenomena of pleasure and pain to which the hedonist appeals as the ultimate factors in a man's choice. They are not mainly phenomena of feeling at all (5.112). Peirce says that, despite his special training in recognizing qualities of feeling, he cannot discover any such quality common to all pains (5.112). All that careful observation reveals is that "there are certain states of mind, especially among states of mind in which Feeling has a large share,

10 The difficulty he felt was something like this: the three universal categories are irreducible; but logic clearly deals with Thirds, ethics with Seconds, and esthetics with Firsts. How then can one consistently seek the source of a Third in a Second and the source of a Second in a First? 
which we have an impulse to get rid of" (5.112). To add that such an impulse is excited by a common quality of feeling is a theory, not a fact. Hedonism, therefore, cannot claim to be a datum of experience although, like any other theory, it appeals to experience for confirmation. Furthermore, granting that the phenomena of pleasure and of pain are prominent only in those states of mind in which feeling is predominant, they do not consist in any common feeling-quality of pleasure or of pain (even supposing that there are such qualities) (5.113). If one analyzes the phenomenon of pain, he will see that it consists in "a Struggle to give a state of mind its quietus" (5.113). It is therefore, in essence, an event, an actuality, and not just a mere quality of feeling, or, in terms of the categories, pain is essentially a Second and not a First, although undoubtedly it is accompanied by a First. A similar analysis of pleasure will reveal that it consists in "a peculiar mode of consciousness allied to the consciousness of making a generalization, in which not Feeling, but rather Cognition is the principle constituent" (5.113). In other words, Peirce analyzes pleasure as a sort of Third-an affair of mind and not of mere conscious feeling. ${ }^{11}$

$\ldots$ and it seems to me that while in esthetic enjoyment we attend to the totality of Feeling-and especially to the total resultant Quality of Feeling presented in the work of art we are contemplating-yet it is a sort of intellectual sympathy, a sense that here is a Feeling that one can comprehend, a reasonable Feeling. I do not succeed in saying exactly what it is, but it is a consciousness belonging to the category of Representation, though representing something in the Category of Quality of Feeling. (5.113)

Thus, to make esthetics the science upon which the other two norma-

11 For Peirce consciousness is merely a collection of qualities of feeling, or rather, qualities of feeling are the contents of consciousness.

"My taste must doubtless be excessively crude, because I have no esthetic education; but as I am at present advised the esthetic Quality appears to me to be the total unanalyzable impression of a reasonableness that has expressed itself in a creation. It is a pure Feeling but a feeling that is the impress of a Reasonableness that Creates. It is the Firstness that truly belongs to a Thirdness in its achievement of Secondness" (from the first draft of Lecture V of the Lectures on Pragmatism. Peirce Papers, \#310). 
tive sciences depend is not to subscribe to hedonism and is not to confuse the categories. The categories are not confused because esthetics deals with the representation (a Third) of a quality of feeling (a First), just as ethics deals with a representation (a Third) of an action (a Second) and logic with a representation of thought (a Third). Again hedonism is avoided because in this view pleasure consists in something intellectual; it is not the case that something is deliberately approved because it is pleasurable, but something is pleasurable (esthetically pleasing) because it is approved. Perhaps it would be more accurate to say that Peirce is saying that something is pleasurable because it is reasonable, and not vice versa. ${ }^{12}$

In the lectures on pragmatism, therefore, Peirce has once and for all linked logical truth and falsity to moral goodness and badness. $\mathrm{He}$ is still not absolutely sure that there is a science of esthetics (so that moral goodness and badness would be a species of esthetic goodness and badness), but he is inclined so to think and assumes that there is for the sake of developing his line of thought (5.129). It is essential to notice that Peirce at this point has made an important connection between goodness and badness and conformity or disconformity to an end or ideal. Normative science in general is the science of the laws of conformity of things to ends; normative sciences in particular are distinguished in terms of what sort of "things" one is considering in relation to their ends.

... esthetics considers those things whose ends are to embody qualities of feeling, ethics those things whose ends lie in action, and logic those things whose end is to represent something. (5.129) ${ }^{13}$

The "things" he is talking about are more precisely aspects or modes of things corresponding to these three universal categories of Firstness, Secondness, and Thirdness. In scholastic terms we might say that Peirce distinguishes these sciences by their "formal objects." Qua

12 Perhaps the reader sees in what direction this line of thinking will take Peirce: the admirable in itself is the growth of reasonableness in the world. Peirce develops this theme at length in a paper called "Ideals of Conduct" part of his Lowell Lectures of 1903 (1.591-615). We will have occasion to take it up in detail in another place.

13 Cf. also $3.430 \mathrm{ff}$. 
sciences, however, each normative science employs representations of its formal object, and these representations are of course Thirds. Qua normative each of these sciences treats its object in its Secondness, precisely because it is engaged in judging good and bad within the phenomena considered.

In the remainder of the section we have been considering (5.130) Peirce argues in much the same way as he did before. Logic criticizes and classifies arguments. This criticism and classification implies qualitative approval (or disapproval) of the arguments so analyzed. In turn approval supposes control of what we approve. Hence inference is a voluntary act. But approval of a voluntary act is a moral approval. Hence logic is a kind of moral conduct and so is subject to ethical norms. At this point, however, Peirce again mentions some lingering doubts about esthetics.

Ethics-the genuine science of normative ethics, as contradistinguished from the branch of anthropology which in our day often passes under the name of ethics-this genuine ethics is the normative science par excellence, because an end-the essential object of normative scienceis germane to a voluntary act in a primary way in which it is germane to nothing else. For that reason I have some lingering doubt as to there being any true normative science of the beautiful. (5.130)

The emphasis has shifted from that of the "Minute Logic." We have seen that there logic upstaged every other consideration to the point that Peirce called pure ethics "pre-normative." Here Peirce stresses the dependence of logic on ethics and he has come to see that ethics, not logic, is the normative science because reasoning in the last analysis is a voluntary act. But precisely because of this insight he finds difficulty in fitting esthetics into the scheme. The problem is always the same: things seem to be beautiful or ugly independently of any purpose (cf. above and our remarks about "the beautiful" being the object of esthetics). Still, if by the "beautiful" we mean what is kalos, what is admirable in itself, Peirce feels that the only kind of goodness such an ideal can have is esthetic, and so the morally good is a species of the esthetically good after all.

On the other hand, an ultimate end of action deliberately 
adopted-that is to say, reasonably adopted-must be a state of things that reasonably recommends itself in itself aside from any ulterior consideration. It must be an admirable ideal, having the only kind of goodness that such an ideal can have; namely, esthetic goodness. From this point of view the morally good appears as a particular species of the esthetically good. (5.130)

But just what is the esthetically good? What is the admirable in itself? In the first place, according to the doctrine of the categories, it must be of the nature of a First. It must be some positive, simple, immediate quality pervading a multitude of parts. It makes no difference what subjective effect that quality may produce in us; it is esthetically good.

In the light of the doctrine of categories I should say that an object, to be esthetically good, must have a multitude of parts so related to one another as to impart a positive simple immediate quality to their totality; and whatever does this is, in so far, esthetically good, no matter what the particular quality of the total may be. If that quality be such as to nauseate us, to scare us, or otherwise disturb us to the point of throwing us out of the mood of esthetic enjoyment ... then the object remains none the less esthetically good, although people in our condition are incapacitated from a calm esthetic contemplation of it. (5.132)

But from this account follow a number of startling and paradoxical conclusions. In the first place, there is no such thing as positive esthetic badness. Everything is what it is, and as such has some quality pervading its totality. Everything, then, to this extent is esthetically good. (The scholastics called this ontological goodness.) In the second place, if one considers goodness and badness as relative terms, then one might also correctly say that there is no such thing as esthetic goodness. This is the very conclusion that Peirce draws (5.132). All that one has is various esthetic qualities, which are what they are.

All there will be will be various esthetic qualities; that is, simple qualities of totalities not capable of full embodiment in the parts, which qualities may be more decided and strong 
in one case than in another. But the very reduction of the intensity may be an esthetic quality; nay, it will be so; and I am seriously inclined to doubt there being any distinction of pure esthetic betterness and worseness. My notion would be that there are innumerable varieties of esthetic quality, but no purely esthetic grade of excellence. (5.132)

What is back of Peirce's continual hesitation about esthetics is perhaps becoming clearer. It seems to be this: normative science supposes criticism and control; but esthetic qualities seem to be just what they are regardless of anything else and so are beyond criticism and beyond control. The distinction of good and bad implies approval and disapproval. But in what sense can one approve or disapprove of something which is ultimate? In a way one can only recognize it for what it is, unless one's approval of an aim makes it ultimate. Peirce, however, cannot subscribe to that without reservation since it would make the ultimate subjective and arbitrary.

Thus Peirce, in the following paragraph, considers another moment in the process of adopting ideals, namely, the instant when an esthetic ideal is proposed as an ultimate end of action. Now it is no longer simply a question of considering the ideal in itself, but a question of one's adopting or rejecting that ideal. Peirce talks in terms of Kant's categorical imperative pronouncing for or against it with this important difference, namely, that while for Kant that imperative is itself beyond our control, for Peirce it is not. The imperative itself is open to criticism and this is what makes it rational (5.133). At this point, then, there is room for a distinction between good and bad aims: a good aim is one that can be consistently pursued; a bad aim is one that cannot. It follows, then, that a bad aim could not be ultimate. ${ }^{14} \mathrm{~A}$ good aim, Peirce tells us, becomes ultimate once it is unfalteringly adopted because then it is beyond criticism (5.133).

The question, therefore, is to ascertain what end or ends are possible, that is, what end or ends can be consistently pursued under all possible circumstances. This is the problem of the summum bonum. The difficulty, however, is that here Peirce makes this inquiry a

14 An ultimate aim is what would be pursued under all possible circumstances (5.134) and hence would not be disturbed by one's subsequent experiences (5.136). 
problem of ethics and not of esthetics as he had done in an earlier paper. Again, the general line of Peirce's thinking in this matter is clear enough, but he is having a great deal of trouble classifying the steps according to the traditional triad of normative sciences. Perhaps at this point it would be well to consider Peirce's final formulation of the normative sciences and see how he recognized and met these diffculties.

In the "Basis of Pragmatism" (1905-06), Peirce in his usual way shows that "the control of thinking with a view to its conformity to a standard or ideal is a special case of the control of action" (1.573). Thus the theory of controlled thinking, "logic,": must be a special determination of the theory of controlled action-what he has up to now called "ethics." The theory of the control of conduct and action in general is the second of the trio of normative sciences and the one "in which the distinctive characters of normative science are most strongly marked." What should this science be called?

Since the normative sciences are usually held to be three, Logic, Ethics, and [Esthetics], and since he [Peirce], too, makes them three, he would term the mid-normative science ethics if this did not seem to be forbidden by the received acception of that term. (1.573)

At last Peirce seems to have become aware of one of the obstacles in his earlier attempts to classify the "mid-portion of coenoscopy"-the usual way in which the term "ethics" had been used. Traditional treatises on ethics included much more than Peirce wanted to include in the mid-normative science. Thus, for instance, they included analyses of the ideal or summum bonum to which action was to conform. Peirce, however, wishes to make the mid-normative science only a theory of the conformity of action to an ideal, reserving the study of the ideal itself for another science, esthetics. This throws a good deal of light on the apparent confusion in Peirce's lectures on pragmatism discussed in the preceding paragraphs. There he was using the term "ethics" in its traditional sense and applying it to the mid-normative science. Hence what he included under "ethics" and "esthetics" overlapped. To make the distinction sharper he proposes new terminology.

$\mathrm{He}$ [Peirce] accordingly proposes to name the mid-normative science, as such (whatever its content may be) antethics, 
that is, that which is put in place of ethics, the usual second member of the trio. It is the writer's opinion that this antethics should be the theory of the conformity of action to an ideal. Its name, as such, will naturally be practics. Ethics is not practics .... (1.573)

Peirce's problem with esthetics had always been to make sense of goodness and badness applied to esthetic qualities since they seemed to be entirely beyond criticism and control. By the time he wrote the "Basis of Pragmatism" a number of considerations had helped him come to a satisfactory solution. The line of reasoning which would offer an answer seems evident. What is required is a distinction between esthetic qualities in themselves, that is, in their own intrinsic reality, and the conscious adoption of them as ideals to be pursued. Similarly, in the case of the ultimate aim, the summum bonum, a distinction needs to be made between its own objective reality and its conscious acceptance and approval. Armed with this sort of distinction one could argue that the business of esthetics is to seek out through reflective analysis (see 1.580) what end is ultimate (can be consistently pursued in any and all circumstances) and to use this as a norm in adopting any particular esthetic quality as an ideal. According to this account of esthetics there would be the necessary element of criticism and control even with respect to the summum bonum, not in the sense that the objective reality of that bonum would be affected, but in the sense that one would accept it and conform to it willingly and deliberately. ${ }^{15}$ The only question is whether or not Peirce had such an explanation in mind.

There can be little real doubt that Peirce did come to this sort of solution, although a detailed proof would require many more pages of analysis than are available. ${ }^{16}$ There is sufficient evidence for our

15 One might refuse to recognize or to accept the ultimate good, but then that would be to act unreasonably and so to act without true liberty. Cf. 1.602: "My account of the facts, you will observe, leaves a man at full liberty, no matter if we grant all that the necessitarians ask. That is, the man can, or if you please is compelled, to make his life more reasonable. What other distinct idea than that, I should be glad to know, can be attached to the word liberty?" Cf. also $5.339 \mathrm{n}$.

16 We think that such a proof would have to consider at least the following: (1) Peirce's distinction between motive and ideal, (2) his real- 
immediate purpose in the following section from the 1906 paper, "Basis of Pragmatism":

Every action has a motive; but an ideal only belongs to a line [of] conduct which is deliberate. To say that conduct is deliberate implies that each action, or each important action, is reviewed by the actor and that his judgment is passed upon it, as to whether he wishes his future conduct to be like that or not. His ideal is the kind of conduct which attracts him upon review. His self-criticism, followed by a more or less conscious resolution that in its turn excites a determination of his habit, will, with the aid of the sequelae, modify a future action; but it will not generally be a moving cause to action. It is an almost purely passive liking for a way of doing whatever he may be moved to do. Although it affects his own conduct, and nobody else's, yet the quality of feeling (for it is merely a quality of feeling) is just the same, whether his own conduct or that of another person, real or imaginary, is the object of the feeling; or whether it be connected with the thought of any action or not. If conduct is to be thoroughly deliberate, the ideal must be a habit of feeling which has grown up under the influence of a course of self-criticisms and of hetero-criticisms; and the theory of the deliberate formation of such habits of feeling is what ought to be meant by esthetics. (1.574)

The first thing to notice is that in this passage it is not a question of the ideal in itself, but rather the ideal as the agent's. It is a question of what attracts him upon review. Thus Peirce has shifted the emphasis from the admirable per se to a consideration of the habit of feeling in the agent in the presence of certain ends proposed as ideals. An end is made the agent's ideal through the mediation of habit, and in its turn habit, by its aspect of efficacious determination, will modify action in terms of the ideal so adopted. The second thing to remark is that the habits of feeling through which one makes an ideal one's own are subject to criticism and control. They develop; they are ization that ideals can influence man's actions in different ways and in different degrees of awareness, and (3) the role of habit in deliberate conduct. We will have something to say about (3) in the course of this study. 
modified; they are corrected. Consequently, the ideals which one adopts are subject to criticism and control-or, more precisely, the adoption of this or that ideal is subject to control. In the case of the ultimate ideal or summum bonum, of course, its deliberate adoption is conditioned only by its recognition, since refusal to make it one's own would involve the living contradiction of a rational man using his reason in order to be irrational. To put it another way, rejection of an ideal recognized as ultimate would be to refuse to accept the inevitable finality of human activity. ${ }^{17}$ The recognition of the summum bonum is a question of comparing experience with the transcendental condition of such an ultimate, namely, that it is such that it can be pursued in any and every circumstance. Thus when the pursuit of an ideal is rendered impossible it cannot be ultimate (cf. $1.599 \mathrm{ff}$.). According to Peirce, then, habits of feeling and the adoption of ideals are subject to criticism and control, and indeed must be if they are to be called reasonable. Thus esthetics is truly a normative science if it be thought of as the science of the deliberate formation of such habits of feeling.

17 This is perhaps possible for more or less long periods of time, but it seems to us that unless one abandon all thinking about the problem, he would sooner or later have to capitulate. 